\title{
Bivalve immunity and response to infections: Are we looking at the right place?
}

$$
\text { Bassem Allam * and Emmanuelle Pales Espinosa }
$$

School of Marine and Atmospheric Sciences, Stony Brook University, Stony Brook, NY 11794-5000

Phone: 1631632 8745, Fax: 16316328915

Email: Bassem.Allam@stonybrook.edu

\section{Abstract}

Significant progress has been made in the understanding of cellular and molecular mediators of immunity in invertebrates in general and bivalve mollusks in particular. Despite this information, there is a lack of understanding of factors affecting animal resistance and specific responses to infections. This in part results from limited consideration of the spatial (and to some extent temporal) heterogeneity of immune responses and very limited information on host-pathogen (and microbes in general) interactions at initial encounter/colonization sites. Of great concern is the fact that most studies on molluscan immunity focus on the circulating hemocytes and the humoral defense factors in the plasma while most relevant host-microbe interactions occur at mucosal interfaces. This paper summarizes information available on the contrasting value of information available on focal and systemic immune responses in infected bivalves, and highlights the role of mucosal immune factors in host-pathogen interactions. Available information underlines the diversity of immune effectors at molluscan mucosal interfaces and highlights the tailored immune response to pathogen stimuli. This context raises fascinating basic research questions around host-microbe crosstalk and feedback controls of these interactions and may lead to novel disease mitigation strategies and improve the assessment of resistant crops or the screening of probiotic candidates. 


\section{Introduction}

The field of bivalve immunity has been a prolific area of research over the last century. Since the pioneering work of Cuenot [1], there was a growing interest in the study of bivalve immunity and in the exploration of mechanisms used by these organisms to fight and resist infectious agents. Initial interest in these questions was driven by a thrive for basic understanding of mollusk immunity in a comparative framework among the invertebrates. Bivalves offer several advantages compared to other invertebrate taxa as they are often easy to collect and raise in laboratory settings, and blood (hemolymph) can be readily harvested and maintained for in vitro investigations. During the last few decades, the acknowledgment of infectious diseases as a major driver for bivalve population dynamics also fueled interest in the immunity of these animals. Currently, there are seven infectious diseases impacting mollusks that are listed by the Office International des Epizooties [2], 5 out of these 7 infections impact bivalves. The increased awareness of infectious diseases affecting these animals was accompanied by a significant growth in bivalve aquaculture leading to the doubling of production in the last 15 years. Today, of disease-resistant varieties of cultured bivalves.

Most prior work on bivalve immunity targeted internal immune factors and activities associated with circulating hemocytes and dissolved humoral factors of the plasma which work in a complementary fashion to neutralize invading organisms [reviewed by 4, 5, 6]. These investigations led to major progress in our understanding of fundamental aspects of bivalve immune functioning and similarities or differences with other taxonomic groups. As in other invertebrates, invaders are detected via humoral and hemocyte-bound recognition factors, 58 triggering the production of cytokines [7] that could mediate the recruitment of additional hemocytes, activation of phagocytosis and the production and/or release of a wide range of antimicrobial compounds. Recent research in bivalves supported the maternal transfer of immune

61 protection [8], identified factors involved in hemocyte production [9; even though a hematopoeitic organ/tissue remains elusive], highlighted the diversity of immune recognition 
molecules [10-12] and supported a certain level of specific immune priming in bivalves [13, 14]. Even though precise mechanisms for "immune memory" have not been fully established in the invertebrates, they are thought to involve recognition factors such as thioester-containing proteins [15], C-type lectins [13] or the Down syndrome cell adhesion molecule or Dscam [16].

The assessment of changes in cellular and humoral effectors of the hemolymph has been a major focus of studies investigating immune responses of bivalves to infections [4]. While such investigations provide a snapshot of systemic alterations caused by infections, they are hardly linkable to "effective immunity" in most cases. The truth is that it is often difficult to identify immune responses proper towards an infection versus systemic changes in defense-related factors as an indirect, general, stress response. This is exacerbated by the dynamic nature of immune responses where early, effectively protective, responses likely differ from late immune alterations. What adds to the ambiguity is the fact that virtually all infectious diseases affecting bivalve mollusks (and most animals for that matter) are initiated at mucosal interfaces while most studies on bivalve response to infections have focused on immune factors present in the circulatory system. Therefore, immune alterations in the circulatory system do not reflect immune responses at the initial infection sites. In particular, the lack of information on the immune landscape at bivalve mucosal barriers hampers the evaluation of early immune responses at these pathogen recruitment foci, therefore limiting our understanding of conditions leading to the success or failure of infection establishment. This provocatively entitled paper presents some of the information available on the spatial heterogeneity of bivalve immune response to infections and highlights the role of mucosal secretions in immunity and hostmicrobe interactions.

\section{Immune response to infections is spatially heterogeneous}

The temporarily dynamic nature of bivalve immune responses to infections has been highlighted in a large number of studies [reviewed by 4]. This has often been shown or suggested to be linked to change in disease stage status over time or to the mobilization of immune effectors towards infection foci resulting in alterations in the circulatory system. For instance, recruitment 
of hemocytes to infection sites (focal inflammation) is a common cellular response in bivalves even though it remains unclear if hemocytes primarily migrate to products released by infectious agents, intact and damaged hemocytes and other host cells already on site, or, most likely, both. Hemocyte trafficking can result in alterations of the number of circulatory hemocytes and a general increase in hemocyte infiltration in affected tissues as shown in typically focal infections such as Roseovarius Oyster Disease (i.e. Juvenile Oyster Disease, caused by the bacterium Roseovarius crassostreae) in the eastern oyster Crassostrea virginica and Brown Ring Disease (BRD; a bacterial disease caused by Vibrio tapetis) in the clam Ruditapes philippinarum. In both of these two shell diseases, infection initiates in the periostracum at the external surface of the mantle and hemocyte counts display a transient increase in hemolymph before a more consistent increase in the extrapallial fluid (located between the mantle and the shell and in direct contact with the infection site) and in the connective tissue underlying the affected mantle epithelia [1720]. Similar localized hemocyte infiltrations have also been documented in other infections affecting bivalve connective tissues such as QPX disease in the hard clam Mercenaria 109

Some relevant questions that then arise are: what value can we infer to alterations visible in the circulatory system? Are these truly indicative of the processes at play during the host-pathogen interactions, particularly during early infection stages? Wouldn't the investigation of immune responses at infection foci be more relevant than the evaluation of systemic responses?

A few recent studies used high throughput transcriptomic methods to contrast focal and systemic immune response in bivalves following infections and showed that the specific activities of hemocytes differed between infection foci and the circulatory system. For example, Allam et al. [22] showed strong contrast in gene transcription levels between hemocytes derived from the circulatory system as compared to hemocytes collected from the extrapallial fluid of clams infected with BRD. Not only expression levels were different for several hundreds of transcripts between hemocytes sourced from both fluids (Figure 1), but trends were even opposed for several dozens of immune transcripts (e.g. decrease in hemolymph and increase in extrapallial fluid, including for immune recognition and antimicrobial proteins) suggesting a tailored immune response at the infection locus. Similar findings were also reported in tissues (mantle) 
125 from clams infected with the thraustochytrid parasite QPX where a strong focal immune 126 signature was also detected [23; Figure 1].

127

128

129

130

131

132

133

134

135

136

137

138

139

140

141

142

143

144

145

146

147

148

149

150

151

152

153

154

155

Even in the case of bivalve "systemic" infections such as those caused by opportunistic bacteria (e.g. many Vibrio species) or more specialized pathogens such as the alveolate Perkinsus marinus (a.k.a. Dermo) or the ascetosporean Haplosporidium nelsoni (a.k.a. MSX) both of which populate the blood stream during advanced infection stages, the understanding of host-pathogen interactions at the infection initiation sites is primary for unraveling factors mediating host susceptibility or resistance to the infection. For example, $P$. marinus infections initiate in pallial organs (mantle, gills and palps) and remain confined there in early infections to become systemic in later stages $[24,25]$. In other words, the parasite reaches the circulatory system only after failure of "peripheral" immune effectors in stopping its progress; so can the assessment of hemolymph factors inform about oyster immune response and resistance? Similarly, oyster infection with $H$. nelsoni was reported to initiate at the gill epithelia where the parasite remains restricted to that epithelia in resistant oysters while it invades underlying connective tissues and the circulatory system in susceptible oysters [26]. Therefore, the main immune barrier to the spread of the infection appears to be associated with processes associated with the epithelia and it is unclear how the evaluation of hemolymph factors can help unravel host defense factors against the infection or identify the biological bases for resistance. Clearly, a higher resolution of the immune landscape at the portal of entry is essential for understanding biological bases of bivalve refraction and resistance to infections.

\section{Enemy at the gate: the uncovered role of mucosal factors in bivalve immunity and resistance to infections}

The success or failure of a pathogen in establishing infection largely depends upon the results of early interactions with its host. For instance, the infectious process aborts if a pathogen is successfully neutralized by the host at a portal of entry [27-29]. Arguably, most research on bivalve immunity has been done on the cellular and humoral factors present in the hemolymph, which is the last defense layer in these organisms where the quantity of microorganisms reaching 
the circulatory system represents an extremely small fraction of those bathing mucosal tissues. This represents a major drawback in our understanding of mechanisms mediating bivalve resistance to infections. In this context, adult marine bivalves are typically resistant to extremely high numbers of pathogenic microbes (e.g. universal pathogens such as Listonella -formerly Vibrio- anguillarum or specific pathogens such as $V$. tapetis) when they are exposed by immersion, but become very sensitive when small amounts of bacteria are directly introduced into their tissues [30-32]. This underlines the importance of external defense barriers in the resistance process. Despite this common understanding, very little attention has been given to defense factors associated with bivalve mucosal surfaces. This section summarizes some of the information available on the characteristics of mucosal tissues and mucus secretions in bivalves and on their role in host-microbe interactions and overall animal health.

As in vertebrates, epithelia lining the digestive tract of bivalves represent an important mucosal interface that can mediate host-microbe interactions. Nevertheless, because of its efficient mechanical and chemical processes, the digestive tract seems to represent a good barrier to infectious agents, and consequently most fatal infections affecting bivalves are initiated in organs exposed to the external environment, such as pallial organs in bivalve mollusks [25, 33-42]. In these animals, respiration and feeding activities expose soft tissues of the pallial organs (mantle, gills, labial palps, foot and body wall) to an extremely large amount of waterborne microbes. For example, oysters can filter over $10 \mathrm{~L} \mathrm{~h}^{-1} \mathrm{~g}^{-1}$ dry tissue [43] equating over 25,000 microbes/second considering a $1 \mathrm{~g}$ oyster and a modest $10^{4}$ microbes $\mathrm{ml}^{-1}$ seawater (microbial concentrations in estuarine areas are often orders of magnitude higher). The convolution of pallial organs also greatly increases the effective surface of these interfaces and enhances their exposure to waterborne microbes, highlighting the need for an efficient defense system associated with the pallial mucosa.

\subsection{Mucus contains a wide array of immune effectors}

The role of mucosal secretions in host-microbe interactions and animal protection is now well recognized across various taxa, particularly among medically-relevant model species. Mucus itself is an excellent physical barrier to cells or microorganisms. The net created by cross-linked 
glycoproteins (mucoproteins matrices) contained in mucus traps microorganisms before reaching the soft tissues. Mucus matrices also contain various cells and bioactive molecules and have gained prominence in the last few decades as a main component of the innate and acquired immune system [44].

In mollusks, mucus is produced from virtually all epithelia [45] and plays a role in several biological functions [46] such as locomotion [47-51], freeze protection [52], desiccation protection [48, 53], attachment [50] and defense against predators [54]. Mucus is also widely used in mollusks to trap and transport particles on ciliated epithelia for cleansing or feeding through mucociliary transport [55]. The importance of mucus in the biology of these animals is well reflected in the energy allocated to mucus production, sometimes exceeding $15 \%$ of energy gained from food [46].

Most prior work investigating bivalve pallial mucus was performed in the framework of studies of the suspension-feeding process where mucus carries particles intended for ingestion or rejection as pseudofeces [reviewed by 56]. The pallial mucus layer is also the first host factor encountered by microbes that attach to the surface of pallial organs before the establishment of mutualistic (e.g. sulfo-oxidant bacteria in gill bacteriocytes) or parasitic associations [reviewed by 57]. In other words, pallial mucus is involved in the processing of any and all waterborne microbes entering the pallial cavity and captured by the pallial organs, regardless of whether it leads to predation, mutualism, commensalism or parasitism. Therefore, an efficient processing of waterborne microbes by pallial mucus is essential for bivalves to maintain their health given the extraordinarily large number of microbes they encounter through their suspension-feeding activity.

In this context, previous studies have shown that bivalve pallial mucus contains agglutinins that interact with various bacterial species [58, 59]. More recent work showed that some of these agglutinins are lectins that bind microbes through protein-carbohydrate interactions [60-62]. Previous studies also reported the presence in pallial mucus of hydrolytic enzymes that likely contribute to host protection, such as lysozyme [63] and proteases [64]. A recent high-throughput proteomics analysis unraveled the diversity of immune proteins present in mucosal secretions 
covering oyster pallial organs [65, Figure 2]. These included a wide array of immune recognition proteins such as lectins (10 proteins, including galactose and mannose-binding lectins), C1qdomain containing proteins (3), and thioester-containing proteins (7). A defensin and a lysozyme were also detected as well as a robust pool of proteases (23) and protease inhibitors (11 proteins). Some of the proteins appear to be regulated via external stimuli as the transcription levels of a mucosal lectin increased significantly in oysters exposed to a bacterial challenge ( $V$. alginolyticus) but only following bath exposure and not bacterial injection into the circulatory system. This result shows that this lectin responds to external cues associated with the presence of pathogens in the pallial cavity but not in tissues highlighting its role in mucosal immunity [62]. Similarly, lysozyme activity in mantle secretions (extrapallial fluid) was shown to increase in clams exposed to bacterial pathogens, supporting the role of these products in immunity [20, 66]. Nevertheless, the contribution of these "peripheral" immune factors to bivalve health remains greatly under-investigated and very likely under-estimated.

\subsection{Mucosal factors interact with microbes and regulate pathogen growth and virulence}

The adhesion of pathogenic microorganisms to mucosal surfaces is considered to be the first step of many infections in vertebrates and invertebrates [67-69]. Glycoproteins and peptidoglycans contained in mucus promote sugar-protein interactions leading to recognition and adhesion of microorganisms via adhesins/lectins that bind specific mucosal ligands. Microbes often have multiple lectins with different carbohydrate specificities, and modulation of surface receptor density or topographical distributions of these receptors on cell membranes regulate adhesion [70-72]. At the same time, host mucus lectins can serve as anchor sites for carbohydrates present on microbial surfaces $[61,73,74]$. Therefore, mucus production and composition have a direct impact on microbes which themselves can regulate mucus secretion and alter these matrices [7581]. In addition to its role as an anchor site, mucus can also trigger microbial machinery needed for host colonization (and invasion in the case of pathogens). For example, adhesion to mucus can trigger the production of various mucolytic strategies to overcome mucus entrapment as shown in Vibrio cholerae [82]. Similarly, exposure to mucus enhances the production of toxins and the in vivo virulence of Escherichia coli in higher vertebrates [83]. 
Previous studies on marine animals also showed that mucus secretions can favor the attachment and growth of adapted (or specialized) microbes and mediate symbiont recognition. For instance, fish mucus contains factors that enhance or inhibit the growth of different bacterial species [8486]. Furthermore, exposure of the fish pathogen Vibrio anguillarum to salmon gastrointestinal mucus enhances virulence by inducing the production of a metalloprotease [87]. Fish skin mucus also induces an over-expression of proteins involved in bacterial motility in Vibrio salmonicida [88]. Similarly, the involvement of mucus in regulating microbial dynamics has been demonstrated in several marine invertebrates. For example, bacterial growth is enhanced, including that of the opportunistic pathogen $V$. alginolyticus, in media supplemented with coral mucus $[89,90]$. Always in corals, bacterial communities living in the surface mucus layer have been found to be different from those present in the water column suggesting that mucus recruits and maintains specific microorganisms [90, 91]. Finally, the mucus of the nematode Laxus oneistus was shown to contains a C-type lectin that has been suggested to facilitate the aggregation and recruitment of symbionts [92].

Even though the examples from mollusks are very limited, growing evidence suggests that the colonization of mucus represents the first step in specific interactions between waterborne microbes and their hosts. In their investigations of host/symbiont association in the squid Euprymna scolopes, Nyholm et al. [93] and Nyholm and McFall-Ngai [94] demonstrated that the symbiont Vibrio fischeri specifically accumulates and remains retained within the mucus covering squid's light organ. Davidson et al. [95] further demonstrated that mucus actually regulates the dynamics of microbial communities of the light organ to favor the survival and growth of $V$. fischeri. These studies concluded that the specificity of the squid-Vibrio symbiosis begins early in the interaction, within the mucus itself. In another squid species (Illex argentinus), mucus was suggested to trap and promote growth microorganisms entering in the diet of young individuals [96]. In symbiotic members of Thyasiridae (venerid bivalves), pallial mucus is thought to represent the main contributor to the recruitment of chemosynthetic bacterial symbionts $[97,98]$. Recent investigations in oysters $(C$. virginica) showed significant regulation of the proliferation and virulence of the alveolate parasite $P$. marinus following exposure to host mucus $[25,99,100]$. While mucus collected from oyster pallial organs enhanced the proliferation of the parasite (mantle in particular), mucus collected from the digestive gland was inhibitory 
(Figure 3). Interestingly, pallial mucus of the non-compatible host Crassostrea gigas (Pacific oyster) was strongly inhibitory suggesting that $P$. marinus host specificity may begin in the mucus [100]. The in vivo virulence of $P$. marinus was also significantly enhanced when the parasite was exposed to pallial mucus from $C$. virginica. Mortality was significantly higher (up to 10 fold) in oysters injected with parasite cultures supplemented with pallial mucus as compared to oysters injected with parasite cells supplemented with digestive mucus or unsupplemented cultures (Figure 3). RNASeq experiments showed that increased in vivo virulence of $P$. marinus following exposure to mucus was associated with a significant upregulation of potent virulence-related factors [99].

\subsection{Mucosal epithelia contribute to microbial homeostasis}

While phagocytic activity of hemocytes is a hallmark of the innate immune system and has been well described in bivalves, the diverse activities of epithelial cells lining mucosal surfaces also contribute to microbial homeostasis at these pathogen portals of entry. Epithelial cells produce and secrete a wide range of bioactive molecules that are embedded in mucus. In addition, virtually all mucosal epithelia of bivalves are capable of endocytosing biotic and abiotic particles and colloids, including epithelial cells lining the external (extrapallial) and internal (pallial) surfaces of the mantle [101-103], the gill [104, 105], or epithelia lining different sections of the digestive gland and gut [106-108]. Phagocytic activity performed by these epithelia provides a dual nutritional/defense function by enhancing the uptake and digestion of food particles and by keeping pathogens in check and limiting infections. Particles phagocytozed by epithelial cells are then exposed to toxic reactive oxygen species produced by the host cells during the respiratory burst associated with phagocytosis and are neutralized by antimicrobial compounds and hydrolytic enzymes released in phagosomes. Microbes that inhibit, or that are able to resist, intracellular killing and digestion can initiate infection in epithelial cells. This is typically the case for members of the Chlamydiales and Rickettsiales that infect mucosal epithelial cells throughout various taxa, including mollusks [109]. 


\subsection{Blood cells associated with mucosal epithelia: protective sentinels or pathogen acquisition} vehicles?

Like most mollusks, bivalves have an open circulatory system populated by hemocytes that circulate in hemolymph vessels and sinuses as well as throughout soft tissues. Mucosal tissues are often well-irrigated by the blood due to their primary role in exchanges with the surrounding environment for processes such as oxygen or nutrient extraction. For that matter, connective tissues of the gills and sub-epithelial tissues along the digestive tract are among the most hemocyte-rich tissues in mollusks. These hemocytes are able to cross the basement membrane to wander at the surface of the epithelial barrier in close association to the mucus layer (Figure 4). Transepithelial migration of immune cells is well described in vertebrates where mucus contains representatives of innate and adaptive immune cells including neutrophils and dendritic cells that cross epithelial surfaces to interact with environmental microbes and mount an appropriate host response [110]. In mollusks, the pioneering works by Yonge [106] and Takatsuki [111] were the first to report the presence of hemocytes associated with mucosal secretions covering the pallial cavity and in the gut lumen. Both authors showed that these hemocytes were functionally active and were capable of phagocytosing biotic and abiotic particles and transferring phagocytosed materials across the epithelial barrier. In fact, several reports suggested hemocytes trafficking across epithelial barriers to be bi-directional, at least in the gut [112]. Interestingly, Feng et al. [112] reported the presence, in oyster circulatory hemocytes, of carotenoid pigments known to be synthesized only in plants, suggesting these pigments to be acquired by hemocytes through phagocytosis of algal cells during excursions into the gut lumen before transmigrating back and carrying these products to the circulatory system. More recently, trans-epithelial migration of hemocytes has been reported in the clam $R$. philippinarum $[113,114]$ and the oyster $C$. virginica [115] were hemocytes were found associated with mucus covering pallial organs. Hemocytes identified in bivalve extrapallial fluid and those associated with pallial mucus are functionally active as demonstrated by their ability to phagocytose biotic and abiotic particles and to secrete hydrolytic and antimicrobial compounds [111, 113-115]. While hemocytes present in the extrapallial compartment are thought to play a role in biomineralization and shell growth, hemocytes lining pallial epithelia (which are in contact with environmental microbes) are thought to play a sentinel role providing a first alert system and to secrete humoral factors that become integral part of the mucus. 
342 These findings provide a body of evidence that can explain how aquatic mollusks sense and respond to changes in the microbial make-up of their environment. In this context, evidence shows the presence in molluscan mucosal secretions of functionally active hemocytes that are capable of phagocytosing microbes before migrating back inside tissues [111, 112, 114, 115]. Through transepithelial migration, oyster hemocytes were shown to translocate within hours from pallial surfaces to underlying tissues and the circulatory system [116]. Therefore, these hemocytes seem to play a sentinel role similar to that of dendritic cells in vertebrates which migrate across epithelial barriers and venture along mucosal surfaces to "sample" environmental microbes [110]. Interestingly, "pallial hemocytes" in oysters had higher phagocytic activity than circulating hemocytes [115]. They also showed epitope signatures (surface carbohydrates and clusters of differentiation) different from those of circulating hemocytes [116] suggesting that they represent a specialized category of hemocytes. Specifically, labeling with the cluster of differentiation 14 (CD14, a receptor of lipopolysaccharides and other PAMPs) was significantly higher in pallial hemocytes as compared to circulatory cells underlining a higher expression of this pattern recognition receptor and highlighting a sentinel role for these cells. The fact that CD14 is a common constituent of mucosal secretions of vertebrates [117] could suggests this may represent a conserved mediator of mucosal innate immunity in metazoans. possibility for these cells to serve as vehicles allowing the acquisition of adapted microbes that

The occurrence of two-way movements of hemocytes across mucosal epithelia raises the are capable of surviving phagocytosis. In fact, our investigations showed the ability of the obligate oyster parasite $P$. marinus uses a Trojan horse strategy to take advantage of transepithelial migration of pallial hemocytes to gain access to the internal tissues of its oyster host (Figure 5) [118]. Furthermore, exposure of naive oysters to P. marinus was shown to increase transepithelial migration of hemocytes likely resulting in higher infection rates [116]. In contrast, exposure of oysters to the opportunistic bacteria $V$. alginolyticus did not cause any change in transmigration suggesting that change in transepithelial migration rates is not a generic response to microbial exposure. Overall, a better characterization of mucosal hemocytes (functional characterization, turnover rate, etc.) is needed for a better evaluation of their role in mucosal immunity and interactions with pathogens. 


\section{Conclusions}

375

376 Significant progress has been made in the understanding of cellular and molecular mediators of 377 immunity in invertebrates in general and bivalve mollusks in particular. Despite this information, 378 there is a lack of understanding of factors affecting animal resistance and specific responses to 379 infections. This in part results from limited consideration of the spatial (and to some extent temporal) heterogeneity of immune responses and very limited information on host-pathogen 381 (and microbes in general) interactions at initial encounter/colonization sites. The 382 refractive/resistance ability of a host to a pathogen may lie in the outcome of these early 383 interactions at infection sites. In this context, a better understanding of microbe-bivalve 384 interactions at mucosal interfaces is particularly promising given the interplay between 385 mutualistic, commensal and pathogenic microbes at these sites. This is supported by a growing 386 body of evidence highlighting the role mucosal microbiomes in regulating host resistance to 387 infection either directly [microbe-microbe interactions; 69, 119, 120] or indirectly via immune 388 stimulation and maturation [44]. Our current understanding underlines the diversity of immune 389 effectors at molluscan mucosal interfaces [65] and highlights the tailored immune response to 390 pathogen stimuli [62]. This context raises fascinating questions around host-microbe crosstalk 391 and feedback controls of these interactions and may lead to novel disease mitigation strategies and improve the assessment of resistant crops or the screening of probiotic candidates.

\section{Acknowledgments}

We thank the many students, collaborators and colleagues who directly or indirectly contributed

398 to the work presented herein. The authors would like to acknowledge financial support provided 399 by the National Science Foundation (projects IOS 1050596 and IOS 1146920) and by the New York Sea Grant program (projects R/XG-19 and R/FBM-34). 


\section{References}

403

404 1. Cuénot, L., Les organes phagocytaires des mollusques. Archives de Zoologie Experimentale et

405

406

407

408

409

410

411

412

413

414

415

416

417

418

419

420

421

422

423

424

425

426

427

428

429

430

431

432

433

434

435

436

437

438

439

440

441

442

443

444

445

446

447

1. Generale, 1914. 54: p. 267-305.

2. OIE. Office International des Epizooties 2016; Available from: http://www.oie.int/en/animalhealth-in-the-world/oie-listed-diseases-2016/.

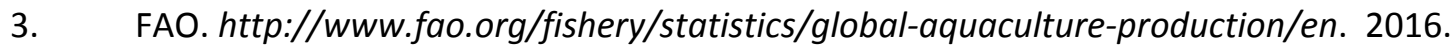

4. Allam, B. and D. Raftos, Immune responses to infectious diseases in bivalves. Journal of invertebrate pathology, 2015. 131: p. 121-136.

5. Song, L., et al., Bivalve immunity, in Invertebrate Immunity. 2010, Springer. p. 44-65.

6. Song, L., et al., The immune system and its modulation mechanism in scallop. Fish \& Shellfish Immunology, 2015. 46(1): p. 65-78.

7. Wu, S.-Z., et al., Interleukin-17 in pearl oyster (Pinctada fucata): Molecular cloning and functional characterization. Fish \& Shellfish Immunology, 2013. 34(5): p. 1050-1056.

8. Wang, L., et al., Maternal immune transfer in mollusc. Developmental \& Comparative Immunology, 2015. 48(2): p. 354-359.

9. $\mathrm{Li}, \mathrm{Y}$. , et al., A cytokine-like factor astakine accelerates the hemocyte production in Pacific oyster Crassostrea gigas. Developmental \& Comparative Immunology, 2016. 55: p. 179-187.

10. Gerdol, M., P. Venier, and A. Pallavicini, The genome of the Pacific oyster Crassostrea gigas brings new insights on the massive expansion of the C1q gene family in Bivalvia. Developmental \& Comparative Immunology, 2015. 49(1): p. 59-71.

11. Zhang, L., L. Li, and G. Zhang, Sequence variability of fibrinogen-related proteins (FREPs) in Crassostrea gigas. Chinese Science Bulletin, 2012. 57(25): p. 3312-3319.

12. Huang, B., et al., Highly diverse fibrinogen-related proteins in the Pacific oyster Crassostrea gigas. Fish \& Shellfish Immunology, 2015. 43(2): p. 485-490.

13. Wang, J., et al., The response of $m R N A$ expression upon secondary challenge with Vibrio anguillarum suggests the involvement of C-lectins in the immune priming of scallop Chlamys farreri. Developmental \& Comparative Immunology, 2013. 40(2): p. 142-147.

14. Zhang, T., et al., The specifically enhanced cellular immune responses in Pacific oyster (Crassostrea gigas) against secondary challenge with Vibrio splendidus. Developmental \& Comparative Immunology, 2014. 45(1): p. 141-150.

15. Rodrigues, J., et al., Hemocyte differentiation mediates innate immune memory in Anopheles gambiae mosquitoes. Science, 2010. 329(5997): p. 1353-1355.

16. Ng, T.H., et al., Review of Dscam-mediated immunity in shrimp and other arthropods. Developmental \& Comparative Immunology, 2014. 46(2): p. 129-138.

17. Ford, S.E. and F.J. Borrero, Epizootiology and pathology of juvenile oyster disease in the Eastern oyster, Crassostrea virginica. Journal of invertebrate pathology, 2001. 78(3): p. 141-154.

18. Paillard, C., K.A. Ashton-Alcox, and S.E. Ford, Changes in bacterial densities and hemocyte parameters in eastern oysters, Crassostrea virginica, affected by juvenile oyster disease. Aquatic Living Resources, 1996. 9: p. 145-158.

19. Perkins, F., The structure of Perkinsus marinus (Mackin, Owen and Collier, 1950) Levine, 1978 with comments on taxonomy and phylogeny of Perkinsus spp. J Shellfish Res, 1996. 15(1): p. 67 87.

20. Allam, B., C. Paillard, and M. Auffret, Alterations in hemolymph and extrapallial fluid parameters in the Manila clam, Ruditapes philippinarum, challenged with the pathogen Vibrio tapetis. Journal of Invertebrate Pathology, 2000. 76(1): p. 63-69. 
21. Dahl, S., J. Thiel, and B. Allam, QPX disease progress in cultured and wild type hard clams in New York waters. Journal of Shellfish Research, 2010. 29(1): p. 83-90.

22. Allam, B., et al., Transcriptional changes in Manila clam Ruditapes philippinarum in response to Brown Ring Disease. Fish \& Shellfish Immunology, 2014.

23. Wang, K., et al. (2016) Clam focal and systemic immune responses to QPX infection revealed by RNA-seq technology. BMC Genomics 17, DOI: 10.1186/s12864-016-2493-9.

24. Dungan, C.F., et al., Identification of Perkinsus marinus portals of entry in histochemical immunoassays of challenged oysters. Journal of Shellfish Research, 1996. 15: p. 500.

25. Allam, B., et al., Early host-pathogen interactions in marine bivalves: Evidence that the alveolate parasite Perkinsus marinus infects through the oyster mantle during rejection of pseudofeces. Journal of Invertebrate Pathology, 2013. 113(1): p. 26-34.

26. Ford, S.E., B. Allam, and Z. Xu, Using bivalves as particle collectors with PCR detection to investigate the environmental distribution of Haplosporidium nelsoni. Diseases of Aquatic Organisms, 2009. 83(2): p. 159.

27. Casadevall, A. and L.a. Pirofski, Host-pathogen interactions: the attributes of virulence. Journal of Infectious Diseases, 2001. 184(3): p. 337-344.

28. Jones, B., L. Pascopella, and S. Falkow, Entry of microbes into the host: using M cells to break the mucosal barrier. Current opinion in immunology, 1995. 7(4): p. 474-478.

29. Liévin-Le Moal, V. and A.L. Servin, The front line of enteric host defense against unwelcome intrusion of harmful microorganisms: mucins, antimicrobial peptides, and microbiota. Clinical Microbiology Reviews, 2006. 19(2): p. 315-337.

30. Tubiash, H.S., Soft-shell clam, Mya arenaria, a convenient laboratory animal or screening pathogens of bivalve mollusks. Proceedings of the Malacological Society of London, 1971. 22(3): p. 321-324.

31. Tubiash, H.S., Single and continuous exposure of the adult American oyster, Crassostrea virginica, to marine vibrios. Canadian Journal of Microbiology, 1974. 20(4): p. 513-517.

32. Allam, B., C. Paillard, and S.E. Ford, Pathogenicity of Vibrio tapetis, the etiological agent of brown ring disease in clams. Dis Aquat Org, 2002. 48: p. 221-231.

33. Burreson, E.M. and S.E. Ford, A review of recent information on the Haplosporidia, with special reference to Haplosporidium nelsoni (MSX disease). Aquatic Living Resources, 2004. 17(4): p. 499-517.

34. Kleeman, S., R. Adlard, and R. Lester, Detection of the initial infective stages of the protozoan parasite Marteilia sydneyi in Saccostrea glomerata and their development through to sporogenesis. International journal for parasitology, 2002. 32(6): p. 767-784.

35. Navas, J., et al., Principal parasites observed in clams, Ruditapes decussatus (L.), Ruditapes philippinarum (Adams et Reeve), Venerupis pullastra (Montagu) and Venerupis aureus (Gmelin), from the Huelva coast (SW Spain). Aquaculture, 1992. 107(2): p. 193-199.

36. Ragone Calvo, L.M., J.G. Walker, and E.M. Burreson, Prevalence and distribution of QPX, Quahog Parasite Unknown, in hard clams, Mercenaria mercenaria in Virginia, USA. Diseases of Aquatic Organisms, 1998. 33(3): p. 209-219.

37. Rodriguez, F. and J. Navas, A comparison of gill and hemolymph assays for the thioglycollate diagnosis of Perkinsus atlanticus (Apicomplexa, Perkinsea) in clams, Ruditapes decussatus (L.) and Ruditapes philippinarum (Adams et Reeve). Aquaculture, 1995. 132(1): p. 145-152.

38. Smolowitz, R., D. Leavitt, and F. Perkins, Observations of a protistan disease similar to QPX in Mercenaria mercenaria (hard clams) from the coast of Massachusetts. Journal of Invertebrate Pathology, 1998. 71(1): p. 9-25.

39. Villalba, A., et al., Perkinsosis in molluscs: A review. Aquatic Living Resources, 2004. 17(4): p. 411-432. 
40. Azevedo, C., Fine-structure of Perkinsus atlanticus $n$ sp (Apicomplexa, Perkinsea) parasite of the clam Ruditapes decussatus from Portugal. Journal of Parasitology, 1989. 75(4): p. 627-635.

41. Ford, S.E., M.M. Chintala, and D. Bushek, Comparison of in vitro-cultured and wild-type Perkinsus marinus. I. Pathogen virulence. Diseases of Aquatic Organisms, 2002. 51(3): p. 187-201.

42. Dahl, S.F., J. Thiel, and B. Allam, Field performance and QPX disease progress in cultured and wild-type strains of Mercenaria mercenaria in New York waters. Journal of Shellfish Research, 2010. 29(1): p. 83-90.

43. Dupuy, C., et al., Feeding rate of the oyster Crassostrea gigas in a natural planktonic community of the Mediterranean Thau Lagoon. Marine Ecology Progress Series, 2000. 205: p. 171-184.

44. Russell, M.W., et al., Overview: The Mucosal Immune System. Mucosal Immunology, 2015: p. 1.

45. Simkiss, k. and K.M. Wilbur, The molluscan epidermis and its secretions. Symposia of the Zoological Society of London 1977. 39: p. 35-76.

46. Davies, M.S. and S.J. Hawkins, Mucus from marine molluscs, in Advances in Marine Biology, Vol 34, J.H.S. Blaxter, A.J. Southward, and P.A. Tyler, Editors. 1998, Academic Press Ltd-Elsevier Science Ltd: London. p. 1-71.

47. Barr, R.A., Some observations on the pedal gland of Milax. Quarterly Journal of Microscopical Science, 1926. 70(2): p. 647-667.

48. Denny, M.W., Invertebrate mucous secretions: functional alternatives to vertebrate paradigms, in Symposia of the Society for Experimental Biology, XLIII. Mucus and related topics, E. Chantler and N.A. Ratcliffe, Editors. 1989, The Company of Biologists Limited: Cambridge p. 337-366.

49. Prezant, R.S. and K. Chalermwat, Flotation of the bivalve Corbicula fluminea as a means of dispersal. Science, 1984. 225(4669): p. 1491-1493.

50. Smith, A.M., The structure and function of adhesive gels from invertebrates. Integrative and comparative biology, 2002. 42(6): p. 1164-1171.

51. Smith, A.M., T.J. Quick, and R.S. Peter, Differences in the composition of adhesive and nonadhesive mucus from the limpet Lottia limatula. The Biological Bulletin, 1999. 196(1): p. 34-44.

52. Hargens, A.R. and S.V. Shabica, Protection against lethal freezing temperatures by mucus in an Antarctic limpet. Cryobiology, 1973. 10(4): p. 331-337.

53. Wolcott, T.G., Physiological ecology and intertidal zonation in limpets (Acmaea): a critical look at" limiting factors". The Biological Bulletin, 1973. 145(2): p. 389-422.

54. Gavagnin, M., et al., Polypropionates from the Mediterranean mollusk Elysia timida. Journal of Natural Products, 1994. 57(2): p. 298-304.

55. Morton, B., The hypobranchial gland in the Bivalvia. Canadian Journal of Zoology, 1977. 55(8): p. 1225-1234.

56. Ward, J.E. and S.E. Shumway, Separating the grain from the chaff: particle selection in suspension- and deposit-feeding bivalves. Journal of Experimental Marine Biology and Ecology, 2004. 300(1-2): p. 83-130.

57. Allam, B. and E. Pales Espinosa, Mucosal immunity in mollusks, in Mucosal Health in Aquaculture, B. Beck and E. Peatman, Editors. 2015, Academic Press. p. 325-370.

58. Fisher, W.S., Occurrence of agglutinins in the pallial cavity mucus of oysters. Journal of Experimental Marine Biology and Ecology, 1992. 162(1): p. 1-13.

59. McDade, J.E. and M.R. Tripp, Mechanism of agglutination of red blood cells by oyster hemolymph. Journal of Invertebrate Pathology, 1967. 9(4): p. 523-\&.

60. Pales Espinosa, E., M. Perrigault, and B. Allam, Identification and molecular characterization of a mucosal lectin (MeML) from the blue mussel Mytilus edulis and its potential role in particle capture. Comparative Biochemistry and Physiology A-Molecular and Integrative Physiology 2010. 156: p. 495-501. 
61. Pales Espinosa, E., et al., Lectins associated with the feeding organs of the oyster, Crassostrea virginica, can mediate particle selection. Biological Bulletin, 2009. 217(2): p. 130-141.

62. Xing, J., et al., Identification, molecular characterization and expression analysis of a mucosal Ctype lectin in the eastern oyster, Crassostrea virginica. Fish and Shellfish Immunology, 2011. 30(3): p. 851-858.

63. McDade, J.E. and M.R. Tripp, Lysozyme in the hemolymph of the oyster, Crassostrea virginica Journal of Invertebrate Pathology, 1967. 9: p. 531-535.

64. Brun, N.T., N.W. Ross, and A.D. Boghen, Changes in the electrophoretic profiles of gill mucus proteases of the Eastern oyster Crassostrea virginica in response to infection by the turbellarian Urastoma cyprinae. Journal of Invertebrate Pathology, 2000. 75(2): p. 163-170.

65. Pales Espinosa, E., A. Koller, and B. Allam, Proteomic characterization of mucosal secretions in the eastern oyster, Crassostrea virginica. Journal of Proteomics, 2016. 132: p. 63-76.

66. Allam, B., et al., Isolation of the pathogen Vibrio tapetis and defense parameters in brown ring diseased Manila clams Ruditapes philippinarum cultivated in England. Diseases of Aquatic Organisms, 2000. 41(2): p. 105-113.

67. Finlay, B.B. and S. Falkow, Common themes in microbial pathogenicity revisited. Microbiology and Molecular Biology Reviews, 1997. 61(2): p. 136-\&.

68. Paerregaard, A., et al., Interactions between Yersinia enterocolitica and rabbit ileal mucus: growth, adhesion, penetration, and subsequent changes in surface hydrophobicity and ability to adhere to ileal brush border membrane vesicles. Infection and Immunity, 1991. 59(1): p. 253260.

69. Tuomola, E.M., A.C. Ouwehand, and S.J. Salminen, The effect of probiotic bacteria on the adhesion of pathogens to human intestinal mucus. Fems Immunology and Medical Microbiology, 1999. 26(2): p. 137-142.

70. Lindén, S., et al., Effects of $\mathrm{pH}$ on Helicobacter pylori binding to human gastric mucins: identification of binding to non-MUC5AC mucins. Biochem. J, 2004. 384: p. 263-270.

71. Mahdavi, J., et al., Helicobacter pylori SabA adhesin in persistent infection and chronic inflammation. Science, 2002. 297(5581): p. 573-578.

72. Teneberg, S., et al., Carbohydrate binding specificity of the neutrophil-activating protein of Helicobacter pylori. Journal of Biological Chemistry, 1997. 272(30): p. 19067-19071.

73. Cash, H.L., et al., Symbiotic bacteria direct expression of an intestinal bactericidal lectin. Science, 2006. 313(5790): p. 1126-1130.

74. Espinosa, E.P., et al., Microalgal cell surface carbohydrates as recognition sites for particle sorting in suspension-feeding bivalves. The Biological Bulletin, 2010. 218(1): p. 75-86.

75. Chadee, K., et al., Mucin and nonmucin secretagogue activity of Entamoeba histolytica and cholera-toxin in rat colon. Gastroenterology, 1991. 100(4): p. 986-997.

76. Deplancke, B. and H.R. Gaskins, Microbial modulation of innate defense: goblet cells and the intestinal mucus layer. The American journal of clinical nutrition, 2001. 73(6): p. 1131S-1141S.

77. Epple, H., et al., Differential stimulation of intestinal mucin secretion by cholera toxin and carbachol. Pflügers Archiv, 1997. 433(5): p. 638-647.

78. Keller, K., M. Olivier, and K. Chadee, The fast release of mucin secretion from human colonic cells induced by Entamoeba histolytica is dependent on contact and protein kinase Cactivation. Archives of medical research, 1992. 23(2): p. 217.

79. Lencer, W., F. Reinhart, and M. Neutra, Interaction of cholera toxin with cloned human goblet cells in monolayer culture. American Journal of Physiology-Gastrointestinal and Liver Physiology, 1990. 258(1): p. G96-G102.

80. Branka, J., et al., Early functional effects of Clostridium difficile toxin A on human colonocytes. Gastroenterology, 1997. 112(6): p. 1887-1894. 
81. Linden, S., et al., Mucins in the mucosal barrier to infection. Mucosal immunology, 2008. 1(3): $p$. 183-197.

82. Silva, A.J., K. Pham, and J.A. Benitez, Haemagglutinin/protease expression and mucin gel penetration in El Tor biotype Vibrio cholerae. Microbiology, 2003. 149(7): p. 1883-1891.

83. Melton-Celsa, A.R., S.C. Darnell, and A.D. O'Brien, Activation of Shiga-like toxins by mouse and human intestinal mucus correlates with virulence of enterohemorrhagic Escherichia coli 091: H21 isolates in orally infected, streptomycin-treated mice. Infection and immunity, 1996. 64(5): p. 1569-1576.

84. Ebran, N., et al., Pore-forming properties and antibacterial activity of proteins extracted from epidermal mucus of fish. Comparative Biochemistry and Physiology A-Molecular and Integrative Physiology, 1999. 122(2): p. 181-189.

85. Nagashima, Y., et al., Purification and characterization of an antibacterial protein in the skin secretion of rockfish Sebastes schlegeli. Comparative Biochemistry and Physiology C-Toxicology \& Pharmacology, 2003. 136(1): p. 63-71.

86. Vine, N.G., W.D. Leukes, and H. Kaiser, In vitro growth characteristics of five candidate aquaculture probiotics and two fish pathogens grown in fish intestinal mucus. Fems Microbiology Letters, 2004. 231(1): p. 145-152.

87. Denkin, S.M. and D.R. Nelson, Induction of protease activity in Vibrio anguillarum by gastrointestinal mucus. Applied and environmental microbiology, 1999. 65(8): p. 3555-3560.

88. Uttakleiv Ræder, l., et al., Effect of fish skin mucus on the soluble proteome of Vibrio salmonicida analysed by 2-D gel electrophoresis and tandem mass spectrometry. Microbial pathogenesis, 2007. 42(1): p. 36-45.

89. Ducklow, H.W. and R. Mitchell, Bacterial populations and adaptations in the mucus layers on living corals. Limnology and Oceanography, 1979. 24(4): p. 715-725.

90. Ritchie, K.B., Regulation of microbial populations by coral surface mucus and mucus-associated bacteria. Marine Ecology Progress Series, 2006. 322: p. 1-14.

91. Brown, B. and J. Bythell, Perspectives on mucus secretion in reef corals. Marine Ecology Progress Series, 2005. 296: p. 291-309.

92. Bulgheresi, S., et al., A new C-type lectin similar to the human immunoreceptor DC-SIGN mediates symbiont acquisition by a marine nematode. Applied and Environmental Microbiology, 2006. 72(4): p. 2950-2956.

93. Nyholm, S.V., et al., Establishment of an animal-bacterial association: Recruiting symbiotic vibrios from the environment. Proceedings of the National Academy of Sciences of the United States of America, 2000. 97(18): p. 10231-10235.

94. Nyholm, S.V. and M.J. McFall-Ngai, Dominance of Vibrio fischeri in secreted mucus outside the light organ of Euprymna scolopes: The first site of symbiont specificity. Applied and Environmental Microbiology, 2003. 69(7): p. 3932-3937.

95. Davidson, S.K., et al., NO means 'yes' in the squid-vibrio symbiosis: nitric oxide (NO) during the initial stages of a beneficial association. Cellular Microbiology, 2004. 6(12): p. 1139-1151.

96. Vidal, E.A. and M. Haimovici, Feeding and the possible role of the proboscis and mucus cover in the ingestion of microorganisms by rhynchoteuthion paralarvae (Cephalopoda:

Ommastrephidae). Bulletin of marine science, 1998. 63(2): p. 305-316.

97. Dufour, S.C., Gill anatomy and the evolution of symbiosis in the bivalve family Thyasiridae. Biological Bulletin, 2005. 208(3): p. 200-212.

98. Southward, E.C., Gill symbionts in Thyasirids and other bivalve molluscs. Journal of the Marine Biological Association of the United Kingdom, 1986. 66(04): p. 889-914. 
99. Pales Espinosa, E., E. Corre, and B. Allam, Pallial mucus of the oyster Crassostrea virginica regulates the expression of putative virulence genes of its pathogen Perkinsus marinus. International journal for parasitology, 2014. 44(5): p. 305-317.

100. Pales Espinosa, E., S.M. Winnicki, and B. Allam, Early host-pathogen interactions in marine bivalves: Pallial mucus of Crassostrea virginica modulates the growth and virulence of its pathogen Perkinsus marinus. Diseases of Aquatic Organisms, 2013. 104(3): p. 237-247.

101. Bevelander, G. and H. Nakahara, Correlation of lysosomal activity and igestion by mantle epithelium. Biological Bulletin, 1966. 131(1): p. 76-\&.

102. McLean, N., Phagocytosis by epidermal-cells of the mantle in Mytilus edulis-l (mollusca, bivalvia). Comparative Biochemistry and Physiology a-Physiology, 1980. 66(2): p. 367-369.

103. Nakahara, H. and G. Bevelander, Ingestion of particulate matter by the outer surface cells of the mollusc mantle. Journal of Morphology, 1967. 122(2): p. 139-146.

104. George, S., B. Pirie, and T. Coombs, The kinetics of accumulation and excretion of ferric hydroxide in Mytilus edulis (I.) and its distribution in the tissues. Journal of Experimental Marine Biology and Ecology, 1976. 23(1): p. 71-84.

105. Johnson, M.A. and M. Le Pennec, Association between the mollusk bivalve Loripes lucinalis and a Chlamydia-like organism, with comments on its pathogenic impact, life-cycle and possible mode of transmission. Marine Biology, 1995. 123(3): p. 523-530.

106. Yonge, C.M., Structure and physiology of the organs of feeding and digestion in Ostrea edulis. Journal of the Marine Biological Association of the United Kingdom (New Series), 1926. 14(02): p. 295-386.

107. Yonge, C.M., Feeding mechanisms in the invertebrates. Biological Reviews, 1928. 3(1): p. 21-76.

108. Yonge, C.M., On Some Aspects of Digestion in Ciliary Feeding Animals. Journal of the Marine Biological Association of the United Kingdom (New Series), 1935. 20(02): p. 341-346.

109. Fryer, J.L. and C.N. Lannan, Rickettsial and chlamydial infections of freshwater and marine fishes, bivalves, and crustaceans. Zoological Studies, 1994. 33(2): p. 95-107.

110. Rescigno, M., et al., Dendritic cells express tight junction proteins and penetrate gut epithelial monolayers to sample bacteria. Nature immunology, 2001. 2(4): p. 361-367.

111. Takatsuki, S.I., On the nature and functions of the amoebocytes of Ostrea edulis. Quarterly Journal of Microscopical Science, 1934. 76(303): p. 379-431.

112. Feng, S., J. Feng, and T. Yamasu, Roles of Mytilus coruscus and Crassostrea gigas blood cells in defense and nutrition, in Comparative pathobiology. 1977, Springer. p. 31-67.

113. Allam, B. and C. Paillard, Defense factors in clam extrapallial fluids. Diseases of Aquatic Organisms, 1998. 33(2): p. 123-128.

114. Allam, B., Role of extrapallial fluids in bivalve immunity: the case of Brown Ring Disease in the clam Ruditapes philippinarum. 1998, University of Western Brittany, Brest, France. p. 204.

115. Lau, J., et al. What are the source and function of hemocytes associated with oyster pallial mucus? 2013.

116. Lau, J., et al. Characterization of hemocytes from different body fluids of the eastern oyster Crassostrea virginica. 2013.

117. Uehara, A., et al., Constitutive expression of a bacterial pattern recognition receptor, CD14, in human salivary glands and secretion as a soluble form in saliva. Clinical and diagnostic laboratory immunology, 2003. 10(2): p. 286-292.

118. Allam, B. and N. Parvez. Uptake of Perkinsus marinus at pallial interfaces in the oyster, Crassostrea virginica. in World Aquaculture Society Meeting. 2007. San Antonio, TX, USA: World Aquaculture Society.

119. Barr, J.J., et al., Bacteriophage adhering to mucus provide a non-host-derived immunity. Proceedings of the National Academy of Sciences, 2013. 110(26): p. 10771-10776. 
685

686

687

688

689

690
120. Mack, D.R., et al., Probiotics inhibit enteropathogenic E. coliadherence in vitro by inducing intestinal mucin gene expression. American Journal of Physiology-Gastrointestinal and Liver Physiology, 1999. 276(4): p. G941-G950. 
Figure 1. Gene transcription profiling (number of differentially-expressed transcripts) contrasting systemic and focal immune responses. A: gene transcription profiling of hemocytes collected 695 from the circulatory system or the extrapallial fluid of Manila clams infected with Brown Ring Disease (Agilent 15K oligoarray data from Allam et al., 2014). B: gene transcription profiling of mantle biopsies from QPX infection foci or symmetrically-located biopsies from the same clams

698 (RNASeq data from Wang et al., 2016).

699

Figure 2. A selection of immune-related proteins identified by liquid chromatography/mass spectrometry in mucus covering the pallial organs (mantle, gills, palps) of the oyster Crassostrea virginica (data from Pales Espinosa et al., 2016).

703

Figure 3. Effect of oyster pallial mucus on Perkinsus marinus growth (A) and virulence (B). In 705 B), P. marinus cultures were supplemented with Crassostrea virginica mucus before injection 706 into the pallial cavity of naive oysters. * indicate significant difference as compared to unsupplemented cultures (data from Pales Espinosa et al., 2013).

Figure 4. A hemocyte transmigrating across the extrapallial epithelium of the clams Mercenaria mercenaria (A) and Ruditapes philippinarum (B). In (A), the hemocyte is seen crossing the 711 basement membrane. In (B), the hemocyte is visible at the apical surface of the epithelial layer. 712 From Allam and Pales Espinosa, 2015.

714 Figure 5. Confocal microscopy images showing a transmigrating pallial hemocyte (A) containing 715 a $P$. marinus cell (B) $42 \mu \mathrm{m}$ below the surface of the mantle pallial epithelium. C: merged 716 pictures. Pallial hemocytes were labeled by adding rhodamine to seawater containing oysters 717 before parasite cells labeled with the vital dye carboxyfluorescein succinimidyl ester were added 718 and incubated for 6 hours. 


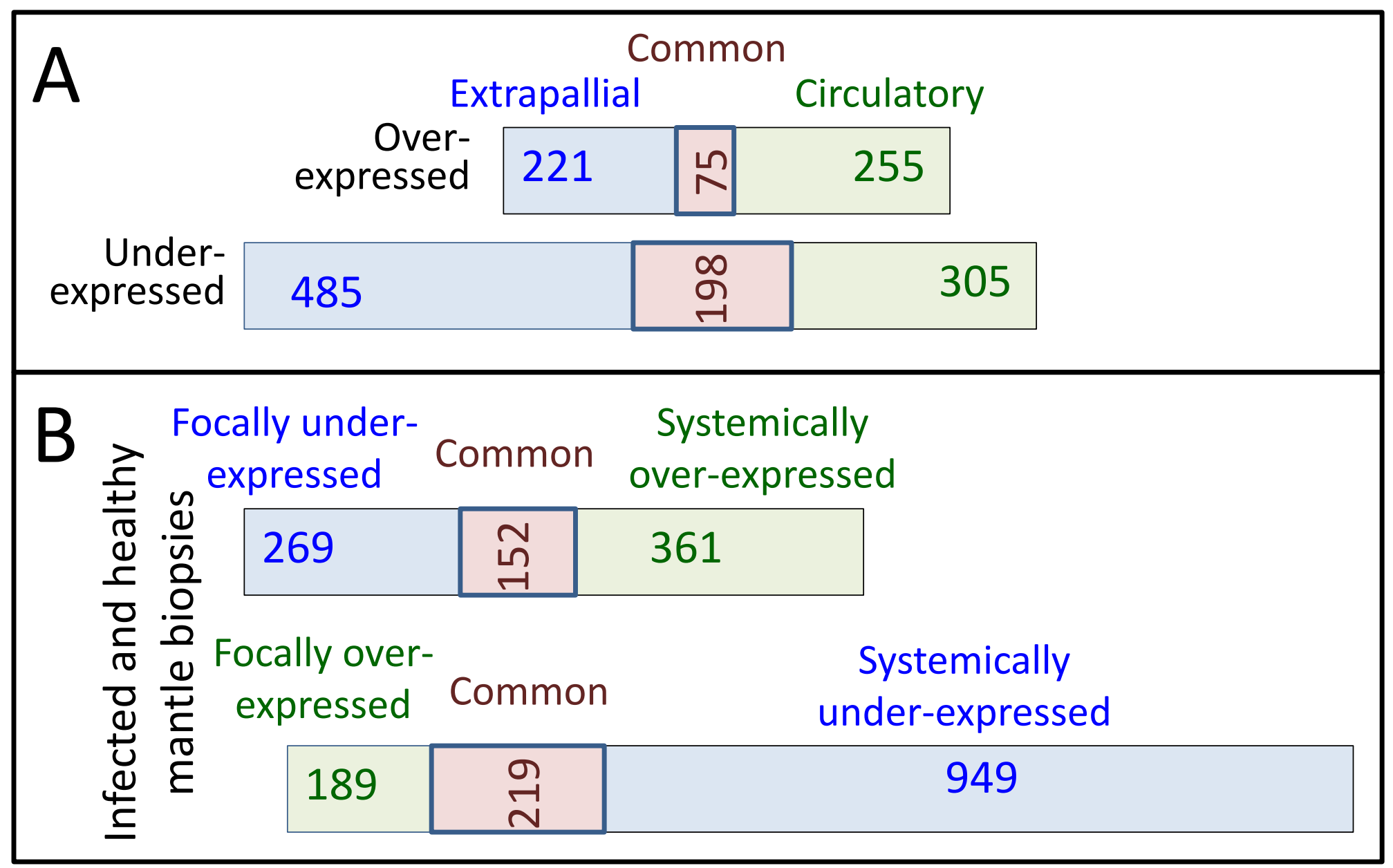

Figure 1. Gene transcription profiling (number of differentially-expressed transcripts) contrasting systemic and focal immune responses. A: gene transcription profiling of hemocytes collected from the circulatory system or the extrapallial fluid of Manila clams infected with Brown Ring Disease (Agilent 15K oligoarray data from Allam et al., 2014). B: gene transcription profiling of mantle biopsies from QPX infection foci or symmetrically-located biopsies from the same clams (RNASeq data from Wang et al., 2016). 


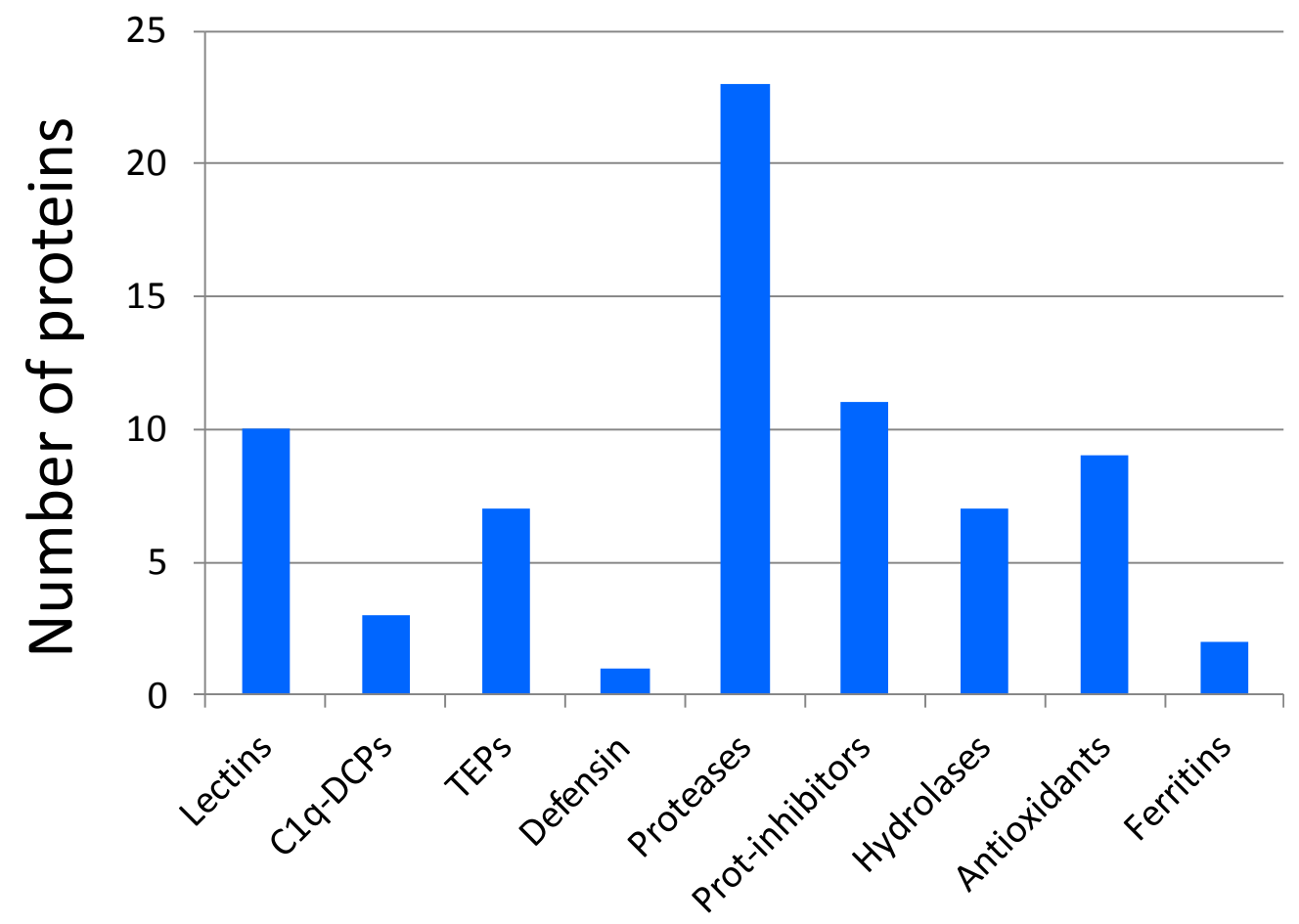

Figure 2. A selection of immune-related proteins identified by liquid chromatography/mass spectrometry in mucus covering the pallial organs (mantle, gills, palps) of the oyster Crassostrea virginica (data from Pales Espinosa et al., 2016). 

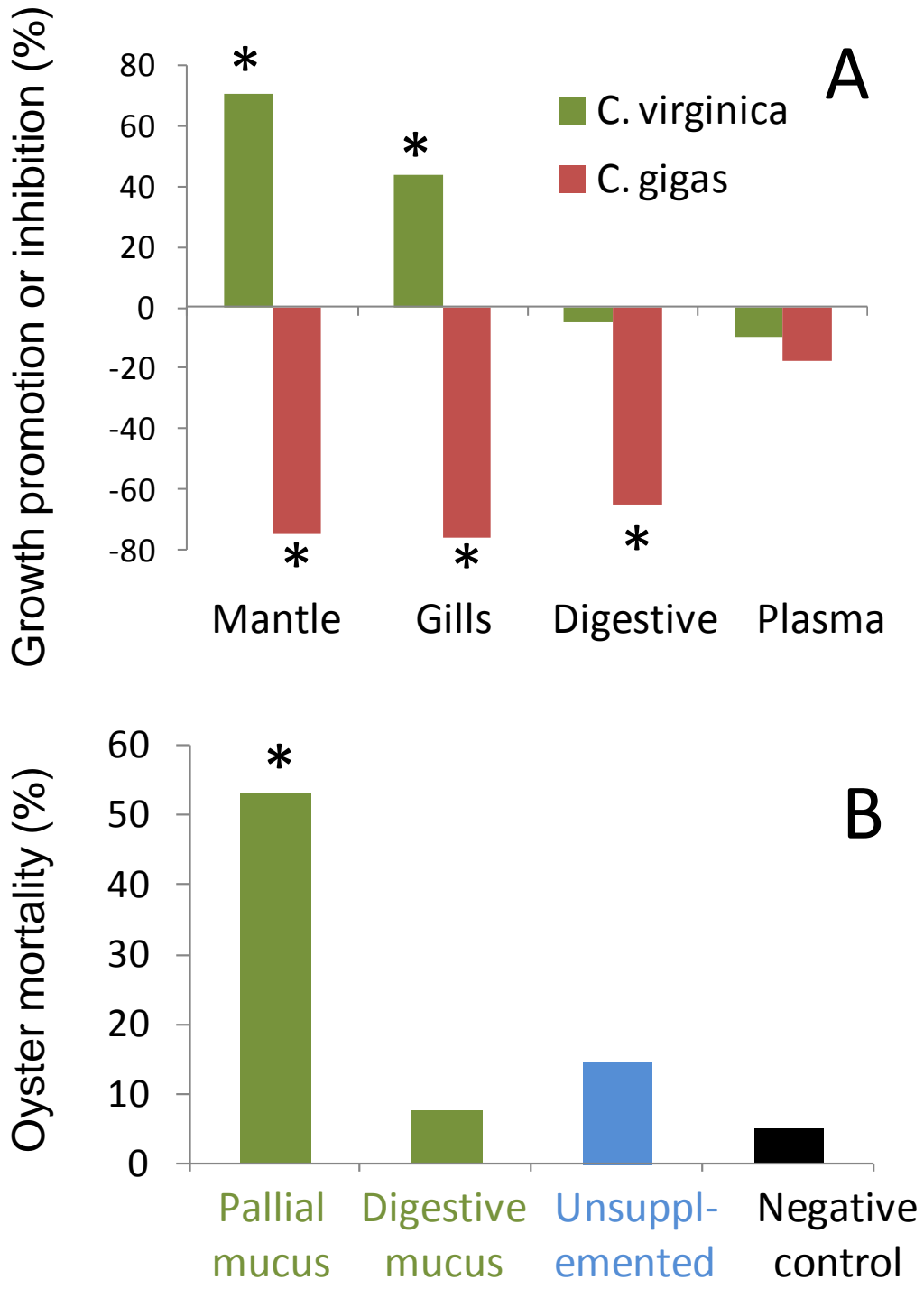

Figure 3. Effect of oyster pallial mucus on Perkinsus marinus growth (A) and virulence (B). In B), P. marinus cultures were supplemented with Crassostrea virginica mucus before injection into the pallial cavity of naive oysters. * indicate significant difference as compared to unsupplemented cultures (data from Pales Espinosa et al., 2013). 

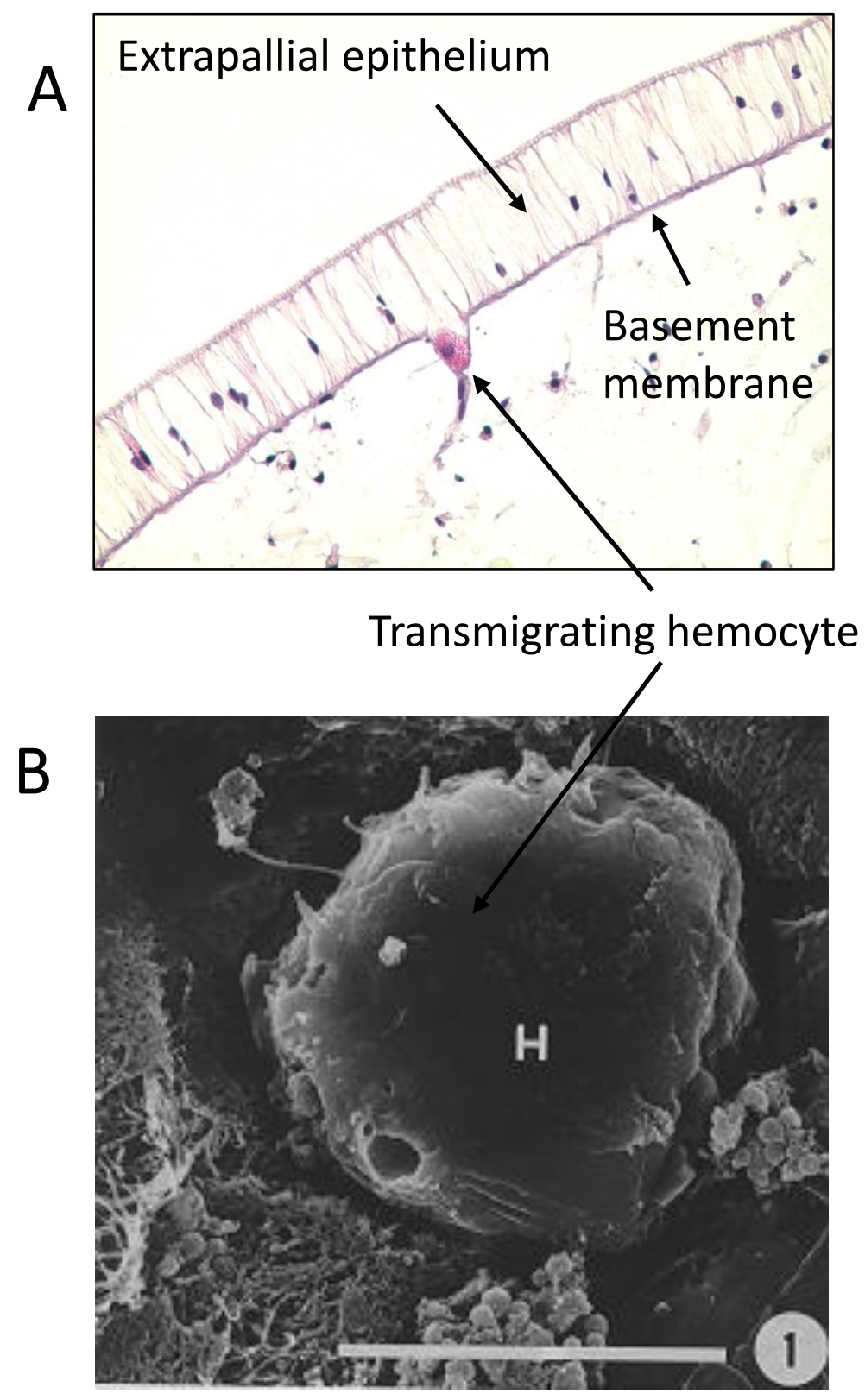

Figure 4. A hemocyte transmigrating across the extrapallial epithelium of the clams Mercenaria mercenaria (A) and Ruditapes philippinarum (B). In $(A)$, the hemocyte is seen crossing the basement membrane. In (B), the hemocyte is visible at the apical surface of the epithelial layer. From Allam and Pales Espinosa, 2015. 


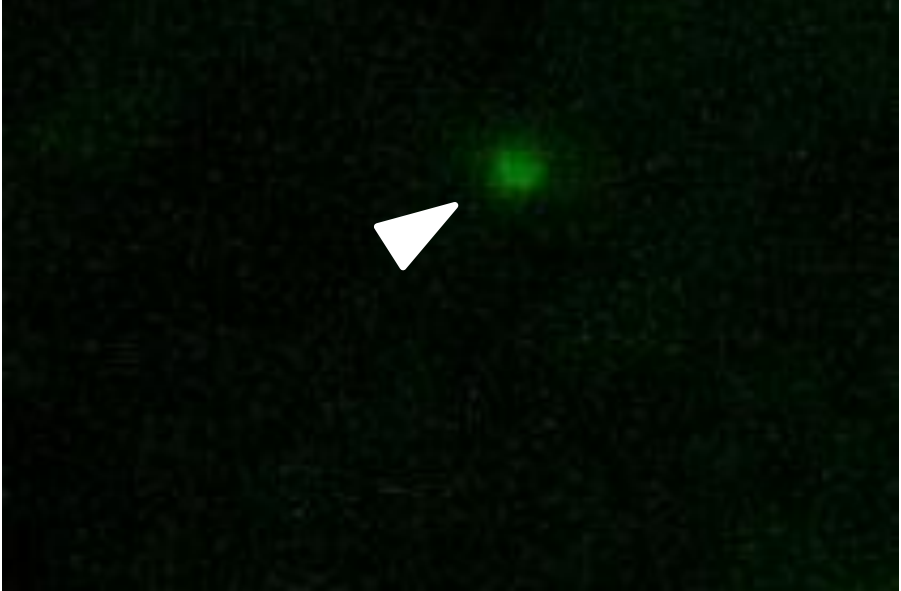

\section{C}

Figure 5. Confocal microscopy images showing a transmigrating pallial hemocyte (A) containing a P. marinus cell (B) $42 \mu \mathrm{m}$ below the surface of the mantle pallial epithelium. C: merged pictures. Pallial hemocytes were labeled by adding rhodamine to seawater containing oysters before parasite cells labeled with the vital dye carboxyfluorescein succinimidyl ester were added and incubated for 6 hours. 